\title{
Wellbeing of Veterinary and Medical Students during COVID-19 Pandemic
}

\section{Hamza Jawad ${ }^{1 *}$, Hiba Qasir ${ }^{2}$, Nasir Iqbal ${ }^{3}$, Javeria Azhar ${ }^{4}$, Arooba Mubeen $^{5}$ and Muhammad Affaq Azhar ${ }^{6}$}

${ }^{1}$ Faculty of Veterinary and Animal Sciences, The Islamia University of Bahawalpur, Bahawalpur, Pakistan

${ }^{2}$ Faculty of Agriculture Sciences, Georg-August-Universitat Gottingen, Gottingen, Germany

${ }^{3}$ Department of Veterinary Surgery and Pet Sciences, University of Veterinary and Animal Sciences, Lahore, Punjab, Pakistan

${ }^{4}$ Department of Botany, The Islamia University of Bahawalpur, Sub Campus Bahawalnagar, Punjab, Pakistan

${ }^{5}$ Department of Environmental Sciences, Faculty of Biosciences, University of Veterinary and Animal Sciences, Lahore, Punjab, Pakistan

${ }^{6}$ Department of Computer Science and IT, The Islamia University of Bahawalpur, Bahawalpur, Pakistan

*Corresponding Author: Hamza Jawad, Faculty of Veterinary and Animal Sciences, The Islamia University of Bahawalpur, Bahawalpur, Punjab, Pakistan.
Received: June 16, 2020

Published: June 27, 2020

(C) All rights are reserved by Hamza Jawad., et al.

\begin{abstract}
COVID-19 (coronavirus diseases 2019) has caused a high rate of anxiety, depression, alcoholism and stress in veterinary and medical students. Prolonged closures have created a financial crisis for students. The poor quality of the online education system is not meeting the needs of these students. Many people suffer from psychological distress due to economic losses and loneliness. This review summarizes data from recent research papers that sheds light on the concerns of veterinary and medical students during the COVID-19 lockdown. Suggestions for future pandemics are also summarized. Medical and veterinary education system need new research on teaching methods, especially from a clinical point of view. In addition to improving the quality of online education in preparation for future crises, student well-being should also be considered to mitigate social crises. Because this COVID-19 pandemic has severely damaged the performance of students in academic and social life. More research is needed to improve the veterinary and medical education system during any.
\end{abstract}

Keywords: COVID-19; Veterinary and Medical Students; Education; Psychological Distress

\section{Introduction}

Medical science is advancing, which has led to a significant reduction in mortality worldwide. Yet some diseases are endangering the health of people all over the world. Among such diseases, viral epidemics and pandemics are at the forefront [1]. In 2019, a new viral disease called COVID-19 was reported [22]. The virus first spread to Wuhan, China on December 31, 2019 [2]. On January 23 , Wuhan was isolated through a lockdown on January 23 to prevent the virus from spreading further. Then, other Chinese cities adopted this method, and by then 50 million people had been affected [3]. The virus has infected 634,835 people worldwide and by March 29, 2020 it has spread to 201 countries [2]. No vaccine or medicine has yet been found against the virus. The only cure we still have is social distance and loneliness [4]. Covid-19 is recognized by the World Health Organization (WHO) on 31 January 2020 as an international public health issue [5]. It is known that the SARS outbreak in 2003 was caused by the Chinese rufous horseshoe bat, so that a virus found in wild animals might be the source of Covid-19 [5,24]. As of March 29, more than 33,997 deaths have been reported worldwide and the count is still ongoing. The China has 
managed to reduce the number of new cases, but other countries such as Italy, Iran, the United States, and many European countries have failed to do so [6].

\section{Method}

We have reviewed research articles, review articles and case studies on student welfare issues during the current COVID-19. The data of these articles are summarized to explain the effect of COVID-19 on students.

\section{Effects on student's health}

The pandemic has increased the chances of deaths due to stress all over the world. Psychological issues have been reported in people, students and patients due to this pandemic [7]. Cases have been reported in which many people have committed suicide due to being infected with the virus or due to the economic crisis. The social situation has caused depression in many people, including students. People who are already dealing with mental illness are at higher risk. A similar case involves a 50-year-old man from southern India who committed suicide because he mistakenly linked his common viral infection to COVID-19 [4]. Various educational institutes in different countries have been shut down to stop the virus from spreading and relieve the health sector of its workload. The closure of schools is affecting the education of $80 \%$ of the world's students. Prolonged school closures could pose a social and health hazard to students living in poverty. One and a half billion young people are now out of education due to school suspensions [8]. Young people face mental health needs because of these restrictions. They are deprived of their resources through schools [9]. According to one estimate, academic pressure puts more stress on students. Isolation and restriction of movement can cause stress in students [2].

COVID-19 has brought a negative mental health condition in medical and veterinary students. Medical students face a lot of demands and a lot of stress, which can affect their mental health $[10,12]$. Due to COVID-19, medical classes have been cancelled and many universities have started online education. One of the most challenging situations caused by the cancellation of classes involves students re-learning in private life after the lockdown is over $[11,19]$. Many medical students are preparing for assessments that require clinical exposure. Lack of exposure can have devastating effects on students' performance in exams. The situation is more complicated for students who were preparing for their final exams. These conditions can cause financial loss to students [12]. Clinical skills cannot be taught online, so students fear that the pandemic will affect their exam performance and negatively affect grades [13]. Adverse educational effects and risks will endanger a student's health $[2,23]$.

\section{Education system during lockdown}

Due to the lockdown, classes are expected to continue through online systems. The situation has widened the gap of learning between the families that earn more and the families that earn less. Students from low-income families do not have the conditions to learn through online lectures. Learning online requires a computer and an internet connection. Many students in world do not have access to such facilities. Some students do not have stable housing. Due to unsafe living conditions, such students are unlikely to complete their homework and online courses [8].

Many students are under pressure due to the sudden withdrawal and cancellation of events such as group studies and graduation ceremonies. Some students have lost their part-time jobs due to the closure of local businesses. Social distance can worsen the abusive situations in an abusive home due to the economic crisis and stress. During previous situations, such as Ebola outbreak, an increase in the child abuse and ill treatment have been reported [9]. The pandemic has devastated airplanes around the world. For many non-national students, traveling home is not possible. It has become difficult for international students to ensure access to food, shelter and security [13].

\section{Stress and alcohol use among students}

The cancellation of the summer internship is a source of concern for students. Due to this pandemic, the pass/fail policy of many universities and colleges is putting pressure on them. They don't know how they will complete competitive courses, from performing arts to chemistry labs experiments [14]. These disturbing situations have created a wave of stress for all students. Students face a lot of psychological effects and find a way to deal with it or find peace of mind [2]. Alcohol use is always associated with some form of stress management. There is a complex relationship between drinking and stress [15]. The isolation circumstances can result in stress-induced alcohol consumption among students. Starting and maintaining alcohol consumption is exacerbated by stress [16]. When risk factors affecting students' lives increase, alcohol and drug use increases. Collective events such as graduation ceremonies are being canceled due to the lockdown, which is putting pressure on students. Additionally, socially relevant factors such as financial problems, lack of communication with family, and friends are also known as stressors. Young adults live in a culture with easy access to legal and illegal materials, including alcohol. In this way, they can easily fall into the trap of alcohol abuse to cope with stress. 
Students who are addicted to alcohol have low self-esteem, low competitiveness and feel more stressed than others [15].

Alcohol consumption is less likely to occur in rural areas than in urban areas where traditional systems have been replaced by Western or modern lifestyles. But students in rural areas do not have the resources to continue their education through the online system. So, they are more likely to adopt alcohol consumption as a relief from stress [15]. The uncertainty and fear caused by pandemics create a workable environment that can promote or give rise to various forms of addiction. One of the main causes of alcohol use is domestic violence. Social distance, poor housing, limited travel and the closure of social resources dramatically increase the risk of domestic violence. In addition to the potential increase in loneliness, the pandemic of negative countermeasures (such as domestic violence) with psychological and economic stress can accumulate into a perfect storm to trigger a wave of excessive drinking [17].

With a weakened immune system, alcoholism can lead to COVID-19 infections at a higher rate. Alcohol disrupts the immune system, both physiologically and adaptively, and significantly deteriorates the body's defenses against infection, and such patients are more likely to develop a COVID-19 infection or any secondary infection. In addition, heavy alcohol use can put them at higher risk for developing other conditions such as obesity and chronic kidney diseases [18]. Severe alcoholic hepatitis patients may not receive average corticosteroid therapy, especially in areas where COVID-19 is more common. Such patients have significantly higher mortality rates. If a student has a bad liver due to alcoholism, COVID-19 infection can be a major decomposing factor [18].

\section{Distance learning during lockdown is a challenge}

Medical and veterinary studies have practical components as an important part of its context. COVID-19 has disturbed the practical education of these students. The social distance requirements associated with this pandemic have had a major impact on veterinary studies [19]. Due to COVID-19, the education curriculum has been converted to online formats. Veterinary students learn in a clinic under the supervision of a professional or college professor or experienced veterinarian [20]. Lack of clinical exposure due to lockdown can have a detrimental effect on students' performance in the future as well as in exams [12]. Each situation has its own merits and demerits. In some areas, innovations in veterinary education have spread to unexpected levels in response to the COVID-19 situation. Online learning has improved engagement, participation in sessions and feedback. Distance learning during lockdown is a challenge, but in many vet schools in world their staff members and students are working on creative ways to deal with it. Once the pandemic is over, there may be practical teaching sessions to prepare skills that were skipped or could not be taught in online lessons [21].

\section{Conclusion}

Psychological stress is mainly related to this COVID-19 pandemic worldwide. Various methods need execution to control this issue. People who have been depressed in the past should be monitored and the news they hear about COVID-19 should be restricted. Mental rehabilitation is needed to support moral, mental, and behavioral values of people. The main stressors for people in this pandemic are financial weakness and educational delays. Governments need to find ways to deal with these stressors in order to provide them with peace of mind [7]. Students are more affected by this pandemic. Governments must find a way to deal with the poverty caused by this pandemic. Students with low income should be monitored for any psychological distress and provided with educational materials and support [8]. There is little research on the psychological effects of pandemic in students. This is an important topic for research [9]. Veterinary and Medical students need more support. They are not above the pressure exerted by this epidemic [10]. There is a need to study how this pandemic is affecting the educational career of students and professionals [11]. It remains to be seen what ease can be found for medical education during this pandemic [12]. Excessive alcohol consumption during this pandemic puts people's health at risk. They need to be made aware of this catastrophic situation [16]. Governments and policy makers need to develop policies to address student-related risks and violence. New rules and regulations are needed to control fake news on social media. Electronic and print media should provide authoritative news, and the introduction of new programs will help students relieve stress caused by pandemics $[17,25]$. These important steps can reduce the suicide rate among Pakistani students and increase their quality of life and development [26].

\section{Bibliography}

1. Ahmed Md Zahir., et al. "Epidemic of COVID-19 in China and associated Psychological Problems." Asian journal of psychiatry (2020): 102092.

2. Zhou Shuang-Jiang., et al. "Prevalence and socio-demographic correlates of psychological health problems in Chinese adolescents during the outbreak of COVID-19". European Child and Adolescent Psychiatry (2020): 1-10. 
3. Wang Cuiyan., et al. "Immediate psychological responses and associated factors during the initial stage of the 2019 coronavirus disease (COVID-19) epidemic among the general population in China". International Journal of Environmental Research and Public Health 17.5 (2020): 1729.

4. Thakur Vikram and Anu Jain. "COVID 2019-suicides: A global psychological pandemic". Brain, Behavior, and Immunity (2020).

5. Zheng Yi., et al. "The effects of misleading media reports about COVID-19 on Chinese tourists' mental health: a perspective article". Anatolia 31.2 (2020): 337-340.

6. Sahu Pradeep. "Closure of universities due to Coronavirus Disease 2019 (COVID-19): impact on education and mental health of students and academic staff". Cureus 12.4 (2020).

7. Cao Wenjun., et al. "The psychological impact of the COVID-19 epidemic on college students in China". Psychiatry Research (2020): 112934.

8. Van Lancker Wim and Zachary Parolin. "COVID-19, school closures, and child poverty: a social crisis in the making". The Lancet Public Health 5.5 (2020): e243-e244.

9. Lee Joyce. "Mental health effects of school closures during COVID-19". The Lancet Child and Adolescent Health 4.6 (2020): 421.

10. Komer Leah. "COVID-19 amongst the Pandemic of Medical Student Mental Health". International Journal of Medical Students 8.1 (2020): 56-57.

11. Ferrel Meganne N and John J Ryan. "The impact of COVID-19 on medical education". Cureus 12.3 (2020).

12. Ahmed Hanad., et al. "COVID-19 and medical education." The Lancet Infectious Diseases (2020).

13. Sahu Pradeep". Closure of Universities Due to Coronavirus Disease 2019 (COVID-19): impact on education and mental health of students and academic staff". Cureus 12.4 (2020).

14. Bansal Priya., et al. "Clinician wellness during the COVID-19 pandemic: extraordinary times and unusual challenges for the allergist/immunologist". The Journal of Allergy and Clinical Immunology (2020).

15. Mphele Seipone BM., et al. "Stress and alcohol use among college students: a case of Molepolole College students". IOSR Journal of Humanities and Social Science 8.3 (2013): 1-6.
16. Clay James M and Matthew O Parker. "Alcohol use and misuse during the COVID-19 pandemic: a potential public health crisis?" The Lancet Public Health 5.5 (2020): e259.

17. Usher Kim., et al. "Family violence and COVID-19: Increased vulnerability and reduced options for support". International Journal of Mental Health Nursing (2020).

18. Da Ben L., et al. "COVID-19 hangover: a rising tide of alcohol use disorder and alcohol-associated liver disease". Hepatology (2020).

19. Brown Natalie., et al. "Learning at home during COVID-19: Effects on vulnerable young Australians" (2020).

20. Rose Suzanne. "Medical student education in the time of COVID-19". JAMA (2020).

21. Bowen Mark. "Covid-19 has changed how we teach students". Veterinary Record 186.14 (2020): 461-461.

22. Luo Min., et al. "The Psychological and Mental Impact of Coronavirus Disease 2019 (COVID-19) on Medical Staff and General Public-A Systematic Review and Meta-analysis". Psychiatry Research (2020): 113190.

23. Hossain Md Mahbub., et al. "Epidemiology of mental health problems in COVID-19: a review." (2020).

24. Aslam Fahim. "COVID-19 and Importance of Social Distancing." (2020).

25. Oliveira GM and MID Rossi. "COVID-19, Social Isolation and Human Stress Comparative Behavior and Welfare.” (2020).

26. Mamun Mohammed A and Irfan Ullah. "COVID-19 suicides in Pakistan, dying off not COVID-19 fear but poverty?-The forthcoming economic challenges for a developing country". Brain, Behavior, and Immunity (2020).

\section{Assets from publication with us}

- Prompt Acknowledgement after receiving the article

- Thorough Double blinded peer review

- Rapid Publication

- Issue of Publication Certificate

- High visibility of your Published work

Website: www.actascientific.com/

Submit Article: www.actascientific.com/submission.php

Email us: editor@actascientific.com

Contact us: +919182824667 